\title{
Lyn is involved in CD24-induced ERK1/2 activation in colorectal cancer
}

\author{
Ning $\mathrm{Su}^{1,2}$, Liang Peng ${ }^{1,2}$, Bingqing Xia ${ }^{1,2}$, Yingying Zhao ${ }^{1,2}$, Angao $\mathrm{Xu}^{3}$, Jing Wang ${ }^{1,2}$, Xinying Wang ${ }^{1,2^{*}}$ \\ and Bo Jiang ${ }^{1,2^{*}}$
}

\begin{abstract}
Background and aim: CD24 expression is associated with human colorectal cancer (CRC). Our previous data indicated that CD24 promoted the proliferation and invasion of colorectal cancer cells through the activation of ERK1/2. Since Src family kinases are frequently deregulated in CRC and closely related to the MAPK signaling pathway, we investigated the impact of Lyn, an important member of SFKs, on CD24-induced ERK1/2 activation in CRC.

Methods and results: The interaction of CD24 and Lyn was identified by co-immunoprecipitation (Co-IP) and ectopic expression of CD24-induced Lyn activation. Inhibition of Lyn activation by phosphatase PP2 in SW480 ${ }^{\mathrm{CD} 24}$ cells abrogated CD24-induced invasion. The results of the Co-IP and immunofluorescence assay revealed that overexpression of CD24 enhanced the interaction of Lyn and ERK1/2 and induced the nuclear translocation of Lyn. However, inhibition of Lyn activity attenuated CD24-induced ERK1/2 activation, and depletion of CD24 disrupted Lyn-ERK1/2 interaction. Immunohistochemistry analysis for 202 cases of CRC showed that the expression of both CD24 and Lyn was positively correlated with tumor grade, stage, lymph node and distant metastasis. Patients with lower expression of CD24 or Lyn had a higher survival rate. The Cox multivariate analysis showed that CD24 expression, but not Lyn expression, was an independent prognostic factor of CRC.
\end{abstract}

Conclusions: Our results suggest that Lyn is involved in CD24-induced ERK1/2 activation in CRC. The expression of CD24 is associated with activation of Lyn and ERK1/2, which might be a novel mechanism related to CD24-mediated regulation of CRC development.

Keywords: CD24, Lyn, ERK1/2, Colorectal cancer

\section{Background}

CD24, a small glycosyl-phosphoinositol-anchored membrane protein ranging from $30-70 \mathrm{kDa}$, consists of a small protein core comprising 27 amino acids, with several potential $\mathrm{O}$ - or N-linked glycosylation sites [1]. CD24 has been identified to be up-regulated in various solid tumors, such as breast cancer [2], prostate cancer [3] and cholangiocarcinoma [4], and its overexpression is usually associated with poor clinical outcomes in some tumor types [2-4]. Chou et al. [5] reported strong cytoplasmic CD24 expression in diffuse- or mixed-type

\footnotetext{
*Correspondence: helen2003517@163.com; drjiang@163.com

'Department of Gastroenterology, Nanfang Hospital, Southern Medical University, Guangzhou 510515, China

${ }^{2}$ Guangdong Provincial key laboratory of Gastroenterology, Guangzhou 510515, China

Full list of author information is available at the end of the article
}

gastric adenocarcinomas. In addition, Sagiv et al. [6] identified that increased expression of CD24 was an early event in the carcinogenesis of colorectal cancer (CRC). Our previous study also revealed that CD24 expression occurred in $92.5 \%$ of human CRC tissue and increased with tumor progression [7]. Furthermore, we showed that CD24 played an important role in the carcinogenesis of CRC.

CD24 is a short mucin-like peptide present at the outer cell surface and lacks a cytoplasmic domain to transduce intracellular signals. However, CD24 has been identified as a novel regulator of proliferation [7], apoptosis [8] and invasion [9] in human cancer. Several ligands of CD24, including P-selectin [10] and Siglec-10 [11], have been identified and are found to be crucial for tumor development. In our previous study, we found that the activation of extracellular signal-regulated

\section{Biomed Central}


kinases 1 and $2($ ERK1/2) and p38 MAPK were dependent of CD24 and required for the proliferation [7] and invasion of CRC cells in vitro and in vivo (unpublished data). Although CD24 is an important player in $\mathrm{CRC}$, the mechanisms of its function in CRC remain unclear. Exploring the mechanisms underlying CD24mediated activation of MAP kinases would be beneficial in for better understanding of the role of CD24 in CRC development.

To this end, the connection between CD24 and MAP kinases in literature has been studied. Zarn et al. found that CD24 localized in glycolipid-enriched membrane (GEM) domains, which are the specialized areas in the plasma membrane signaling platforms, and associated with Lyn in an erythroleukemia cell line [12]. Moreover, Petra et al. showed that CD24 interacted with c-Src and promoted its activity within lipid rafts in breast cancer cells [13]. Furthermore, many studies have suggested that Src family kinases (SFKs) are located upstream of MAPKs cascades in several receptor signaling systems [14]. SFKs are a family of non receptor-type tyrosine kinases and include at least nine highly homologous proteins in mammals $[15,16]$. Lyn is an important member of the SFKs and widely expressed in B-lymphocytes and myeloid cells. Lyn establishes thresholds by acting as both a positive and negative modulator of a variety of signaling responses [17]. Furthermore, aberrant activation of Lyn has been implicated in variety of human tumors, including breast cancer $[18,19]$, prostate cancer, glioblastoma and CRC [20,21]. Therefore, we hypothesize that SFKs are involved in the CD24-induced ERK1/2 activation. In the present study, we examined the correlation between CD24 and Lyn in CRC. Our results revealed that CD24 interacted with Lyn and induced the activation and nuclear translocation of Lyn. In contrast, the inactivation of Lyn abrogated CD24-induced cell invasion and ERK1/2 activation in CRC cells. Analysis of CRC tissues with immunohistochemistry staining showed that the expression of CD24 and Lyn was positively correlated and associated with tumor stage and lymph node and distant metastasis. Our study suggests that the expression of CD24 is associated with the activation of Lyn and ERK1/2, which may be a novel mechanism related to CD24-mediated regulation of CRC development.

\section{Results}

\section{Lyn interacted with CD24 and was activated by CD24 in} CRC cells

To investigate the association of CD24 and SFKs, we examined the activation of SFKs, including Src, Lyn, Fyn and lck in SW480 ${ }^{\mathrm{CD} 24}$ cells and SW480 vector and parental cells. The results showed that ectopic expression of CD24 increased the phosphorylation level of Lyn, but not Src, Fyn or lck (Figure 1A), suggesting that CD24 specifically induced the activation of Lyn, which is a signaling molecule anchoring to plasma membrane. The densitometry results of Figure 1A are shown in Additional file 1: Figure S1. To determine whether there was an interaction between CD24 and Lyn, we performed a CO-IP assay. The results revealed that endogenous or ectopic Lyn were co-precipitated with CD24 in both SW480 ${ }^{\mathrm{VEC}}$ and SW480 ${ }^{\mathrm{CD} 24}$ cells when using an anti-Lyn antibody. This interaction was also confirmed in the reciprocal immunoprecipitation with anti-CD24 antibody (Figure 1B), indicating that endogenous CD24 was capable of binding to Lyn, but binding was weaker than that of the ectopic CD24. Furthermore, the increasing amount of immuneprecipitates in SW480 ${ }^{\mathrm{CD} 24}$ cells suggested that the overexpression of CD24 might promote the CD24-Lyn interaction in a direct or indirect manner. Consistent with this observation, the depletion of CD24, using a specific siRNA in SW620 cells, significantly reduced immunoprecipitates in the CO-IP assay (Figure 1C).

\section{Ectopically expressed CD24 promoted cell invasion and} induced Lyn activation and translocation into the nucleus

We next examined the effect of ectopic expression of CD24 by transfection with a pcDNA3.1(+)-CD24 expression plasmid [7] on the invasion capability of SW480 cells using a cell invasion kit. Invasion capability was quantified as the percentage of invasive cells compared to the total number cells. Representative images of invasive cells of each group are shown in Figure 2A (upper, original magnification, 200x). We observed a 2.15-fold increase in cellular invasion in cells transfected with the pcDNA3.1(+)-CD24 plasmid compared with the control cells (Figure 2B) $(\mathrm{p}<0.05)$. The expression levels of CD24 and the phosphorylation of Lyn were assessed by Western blot analysis. There was an increase in Lyn phosphorylation (Y396) in SW480 ${ }^{\text {CD24 }}$ cells as compared to SW480 ${ }^{\mathrm{VEC}}$ cells $(\mathrm{p}<0.05)$ (Figure $2 \mathrm{C}$ ). To investigate the role of Lyn in CD24-mediated cell invasiveness, cells were treated with $10 \mu \mathrm{M}$ PP2 and tested using a cell invasion assay. The percentage of cells that migrated through the filters from different groups was shown in Figure 2A and B. Similar results were obtained in SW620 cells (data not shown).

Since previous studies showed that distinct localization of Lyn was critical for its function, the cellular localization of Lyn was examined by analysis of dual immunofluorescence staining in this study. As shown in Figure 2D, endogenous phospho-Lyn (green) in control cells was weak and expressed throughout the entire cells (left panels), whereas phospho-Lyn in CD24 expressing cells was more prominent and more intense in the nucleus (right panels). These findings suggested that CD24 could induce Lyn activation and translocation into the nucleus. 


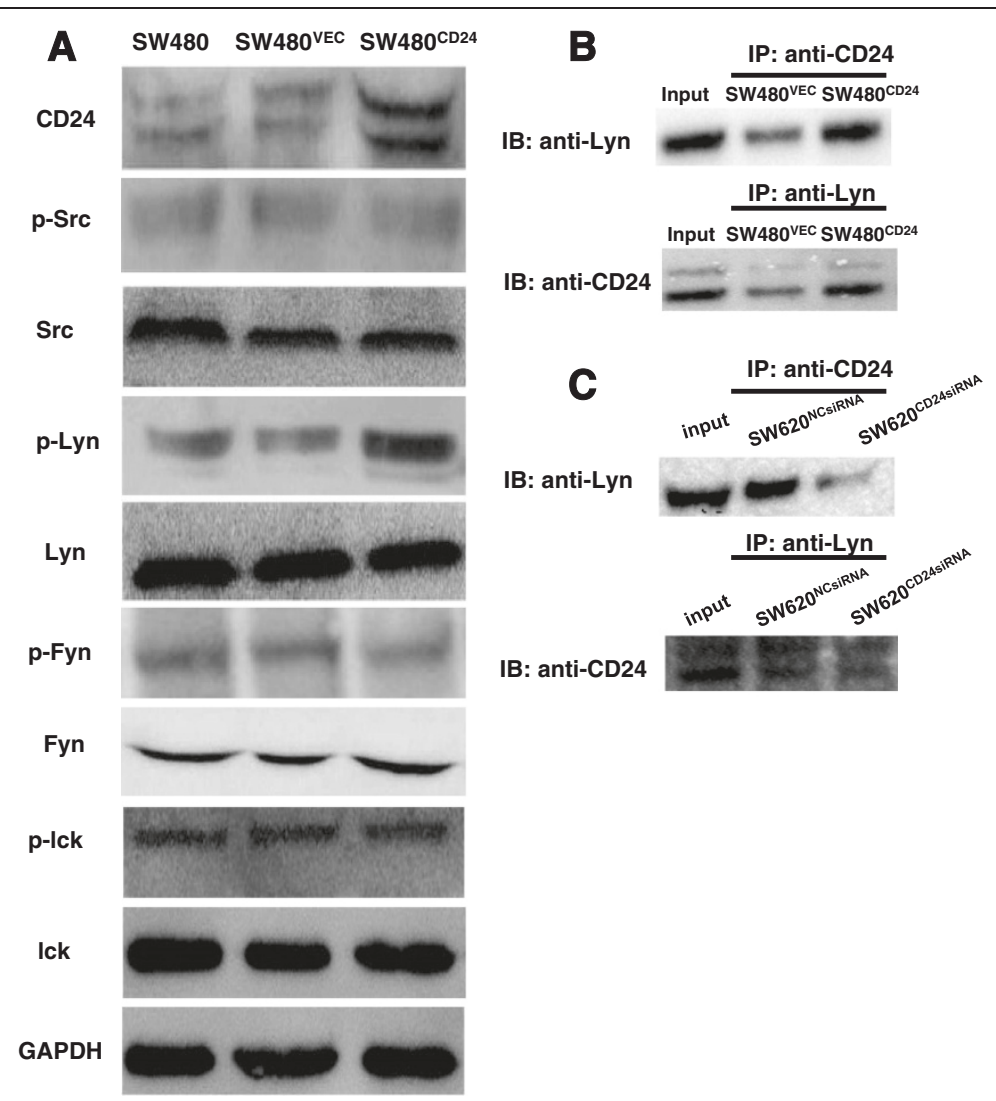

Figure 1 Interaction between CD24 and Lyn. A. Immunoblot analysis for phosphorylation levels of Src, Lyn, Fyn and Ick in SW480 CD24 and vehicle control cells. GAPDH served as an internal control. All of these pictures were representatives of three independent experiments. B. The interaction between Lyn and CD24 was examined in SW480 ${ }^{\mathrm{CD} 24}$ (lane 2) and SW480 VEC (lane 3) cells. Immunoprecipitation was performed with an anti-CD24 antibody, and normal rabbit immunoglobulin G (lg G) served as a control. Western blotting was performed with an anti-Lyn antibody. Input (lane 1) is 1\% of the extract from untreated cells. C. CD24 was depleted with CD24 specific siRNA in SW620 cells. Cell lysates were immunoprecipitated with an anti-CD24 antibody and Western blotting was performed with anti-Lyn antibody.

Immunostaining of Lyn strongly correlated with CD24 expression in human CRC tissues and cancer progression To confirm the correlation between CD24 and Lyn in vivo, immunohistochemical staining was performed in serial sections of human CRC tissues. Lyn and CD24 staining were present mainly in the membrane and/or cytoplasm (Figure 3) and were positively correlated $(\mathrm{r}=0.443, \mathrm{p}<0.05)($ Table 1$)$.

Immunohistochemical staining of the CRC tissue showed that CD24 and Lyn had different degrees of staining. For CD24 staining, 51\% of the CRC tissues showed positive and $49 \%$ showed moderate or strongly positive staining, while its expression in adjacent normal mucosa was either absent or barely detectable. For Lyn staining, $56 \%$ of the CRC tissure showed positive and $44 \%$ showed moderately or strongly positive staining, while its expression in adjacent normal mucosa was either absent or barely detectable.

There was a significantly positive correlation between CD24 expression and tumor grade, tumor stage, invasion depth and lymph node and distant metastasis $(\mathrm{p}<0.05)$, while no correlation was observed between CD24 expression and age, sex, localization and tumor size (Figure 3 and Table 2). Lyn expression correlations were similar to CD24 expression. Our results showed that CD24 and Lyn expression increased with tumor progression.

\section{Inactivation of Lyn inhibited CD24-induced ERK1/2 activation}

In our previous study, we found that CD24 induced the activation of ERK1/2 and p38 MAPK. To explore the mechanism underlying CD24-induced ERK1/2 and p38 MAPK activation, PP2, a specific inhibitor of SFKs, was used in this study. We exposed SW480 ${ }^{\mathrm{CD} 24}$ cells to a dose range of PP2, as indicated in Figure 4A, followed by Western blot analysis of the phosphorylation of Lyn, Erk1/2, and p38 MAPK.

Our data showed that the phosphorylation level of Lyn and ERK1/2 decreased in PP2 treated SW480 ${ }^{\mathrm{CD} 24}$ cells in a dose-dependent manner and peaked at $20 \mu \mathrm{M}$ of 
A
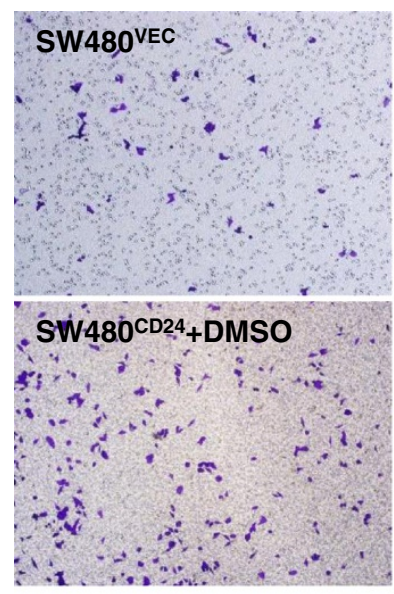

C

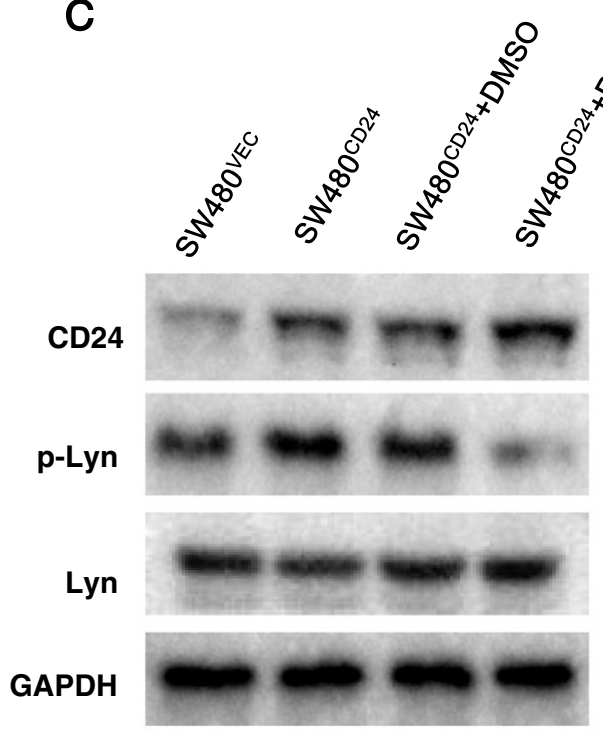

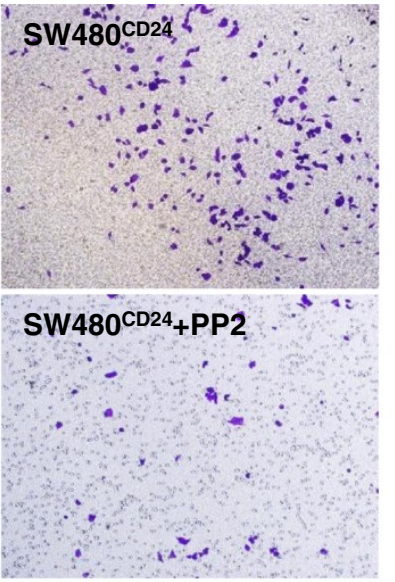

B

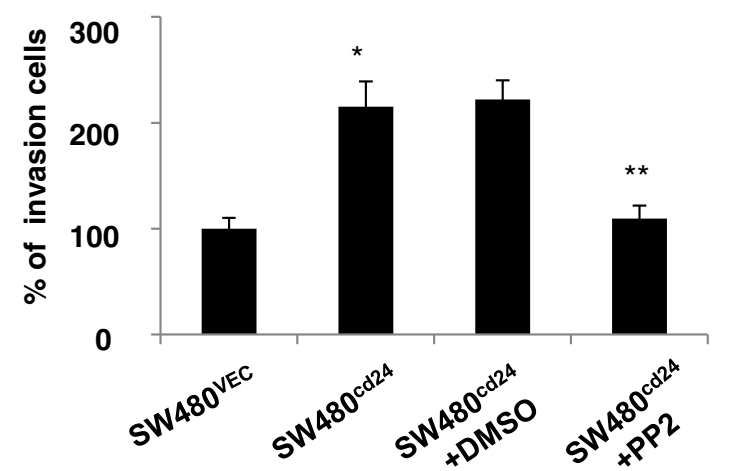

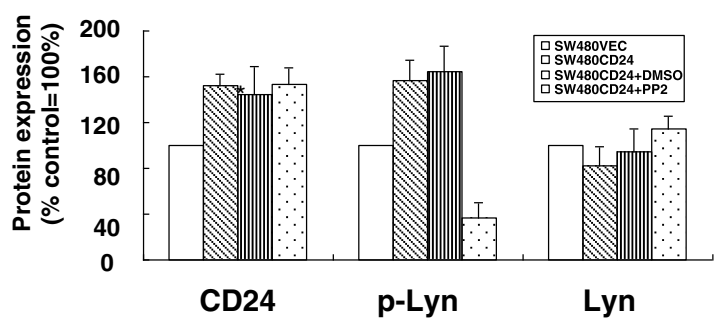
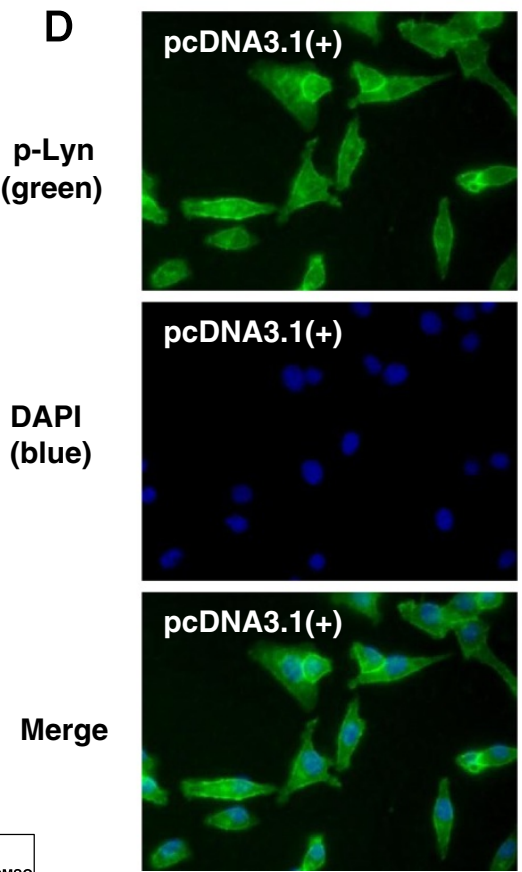
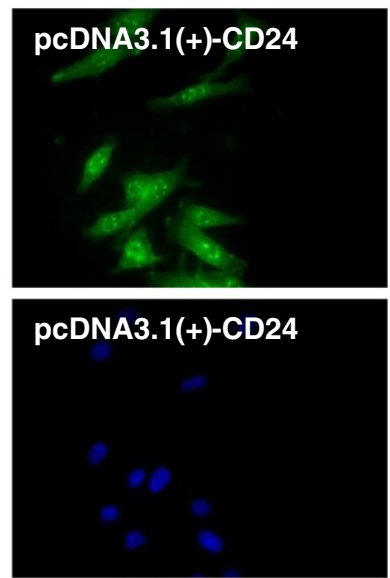

pcDNA3.1(+)-CD24

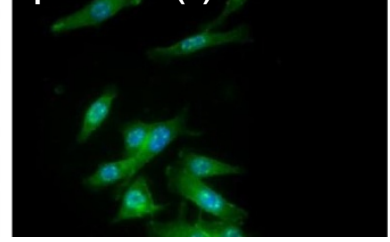

Figure 2 Inhibition of Lyn activation attenuated CD24-induced CRC cell invasion. A. Representative images from the cell invasion assay. SW480 ${ }^{\mathrm{CD} 24}$ cells or vehicle control cells were seeded into transwell chambers coated with Matrigel and $10 \mu \mathrm{M}$ PP2 was added $24 \mathrm{~h}$ later and kept for 30 min. The cell invasion assay was performed at $24 \mathrm{~h}$ after PP2 treatment. CD24 increased the capacity of SW480 cells to migrate through the filters compared with the controls cells (upper). Furthermore, the migration capacity of the SW480 ${ }^{\mathrm{CD} 24}$ cells that were treated by PP2 (10 $\mu$ M) was inhibited (bottom). B. Quantification of cell invasion. Invasive activity was determined as the percent invasion of the control SW480 cells through the Matrigel membrane. Values shown are means \pm standard errors (SE) for three independent experiments. ${ }^{*} \mathrm{P}<0.05$ between SW480 ${ }^{\text {VEC }}$ and SW480 ${ }^{\text {CD24 }}$ cells; ${ }^{* *} \mathrm{P}<0.05$ between $\left(S W 480^{\mathrm{CD} 24}+\mathrm{DMSO}\right)$ and (SW480 $\left.{ }^{\mathrm{CD} 24}+\mathrm{PP} 2\right)$ cells. C. Western blotting analysis showed the phosphorylation of Lyn was induced by the over-expression of CD24 (lane 2) and the activation of Lyn was inhibited by PP2 (lane 4). GAPDH served as a loading control. Bar graph depicted the quantitative analysis for protein expression and the expression of each protein was normalized to GAPDH. D. Immunofluorescent staining of cells transfected with a pcDNA3.1(+)-CD24 plasmid. SW480 cells were transfected with a CD24 expression plasmid or vehicle control. After 24 h, cells were fixed, permeabilized and stained with 4,6-diamidino-2-phenylindole (DAPl; blue) and Lyn (green). In the cells with overexpressed CD24, Lyn was activated. phospho-Lyn was more intense in the nucleus. 


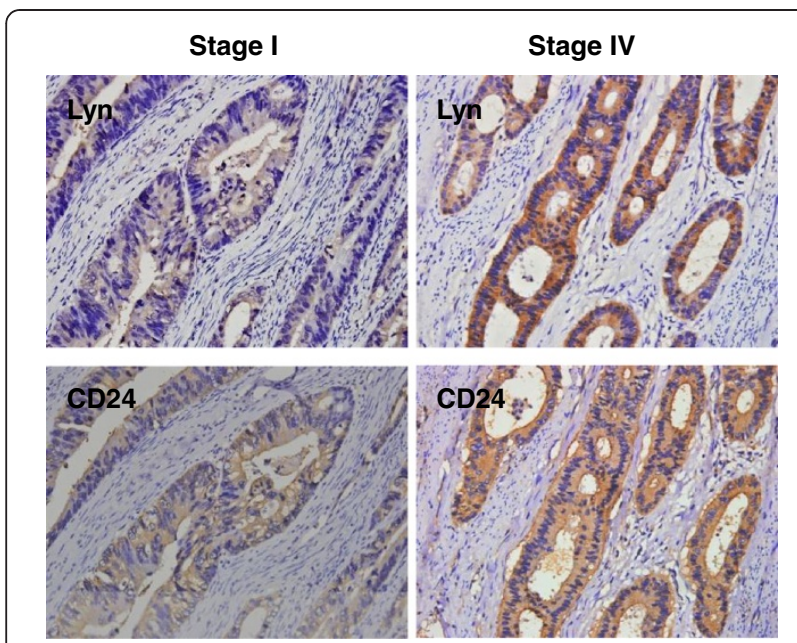

Figure 3 The representative pictures of immunohistochemical staining for Lyn and CD24 in serial sections of CRC tissues with different stages (left: stage I; right: stage IV). (original

magnification $=400 x$ ). Lyn (upper) and CD24 (bottom) showed weak expression in primary cancer tissues (stage I) and strong expression in metastatic cancer tissues (stage IV).

PP2 (Figure 4A). However, the phosphorylation level of p38 MAPK was not impacted by PP2. The IC50 occurred at $10 \mu \mathrm{M}$ PP2 in the preliminary study (data not shown); therefore, we chose $10 \mu \mathrm{M}$ as a standard dose in this study.

CD24 was depleted by a specific siRNA for CD24, which led to the reduction of the phosphorylation of Lyn, ERK1/ 2 and p38 MAPK in SW480 ${ }^{\text {CD24 }}$ cells (Figure 4B). CD24 specific siRNA and PP2 synergistically inactivated ERK1/ 2, but not p38MAPK in both SW480 ${ }^{\text {CD24 }}$ (Figure 4B) and SW620 cells (data not shown). We used another CD24 siRNA (CD24 siRNA-2) to confirm these data. CD24 siRNA-2 showed a similar effect (Additional file 1: Figure S2). To identify the role of Lyn in the CD24-mediated activation of ERK, Lyn was also depleted with a Lyn specific siRNA. The phosphorylation level of ERK1/2 was dramatically decreased in Lyn depleted SW620 cells (Figure 4C), suggesting that inactivation of Lyn could attenuate CD24-induced ERK1/2 activation. Means \pm standard errors (SE) for three independent experiments for Figure 4 are shown in Additional file 1: Figure S3.

Table 1 The correlation of CD24 and Lyn expression in 202 CRC patients

\begin{tabular}{|c|c|c|c|c|c|c|}
\hline \multirow[t]{2}{*}{ CD24 } & \multicolumn{4}{|c|}{ Lyn } & \multirow[t]{2}{*}{$r$} & \multirow[t]{2}{*}{$P$} \\
\hline & - & + & ++ & +++ & & \\
\hline- & 4 & 2 & 0 & 0 & 0.443 & 0.000 \\
\hline+ & 6 & 72 & 12 & 8 & & \\
\hline++ & 2 & 18 & 54 & 6 & & \\
\hline+++ & 2 & 6 & 6 & 4 & & \\
\hline
\end{tabular}

Expression of ectopic CD24 enhanced the interaction of Lyn and ERK1/2 and induced the nuclear translocation of Lyn

SFKs are the upstream modulator of MAP kinases in several receptor signaling pathways. To examine the interaction of Lyn and ERK1/2, as well as the involved regulation of CD24, CO-IP was performed for the interaction of Lyn and ERK. As shown in Figure 5A, the interaction between Lyn and ERK1/2 was identified in SW480 CD24, but not in SW480 ${ }^{\mathrm{VEC}}$ cells, indicating that CD24 could enhance the binding of Lyn to ERK1/2. Our data also showed that the interaction between Lyn and ERK1/2 in SW620 cells, a CD24 abundant cell line, was disrupted when CD24 was depleted by CD24 siRNA (Figure 5B). These data supported the hypothesis that Lyn interacted with ERK1/2 directly or indirectly in a CD24-dependent manner. Furthermore, we examined the effect of ectopically expressed CD24 on the location of Lyn-ERK1/2. Nuclear accumulations of Lyn and ERK1/2 were observed with an immunofluorescence microscopy in ectopic CD24 expressed cells (Figure 5C).

The expression of CD24 and Lyn was associated with the poor prognosis of CRC patients, and CD24 was an independent prognostic factor of CRC

To investigate the prognostic value of CD24 and Lyn, the association of CD24 and Lyn with an overall survival was evaluated using Kaplan-Meier survival curves with the log-rank test. Seventy-four CRC patients were enrolled for this analysis. The follow-up time ranged from 1 to 60 months. The median survival time of the group with low expression of Lyn was 54.101 months, and the cumulative 1-, 3- and 5-year survival rates were 90\%, $85 \%$ and $83 \%$, respectively. The median survival time of the high expression group was 36.641 months, and the 1 -, 3- and 5-year survival rates were $61 \%, 54 \%$ and $50 \%$, respectively. The difference between the groups was significant. The median survival time of the group with low expression of CD24 was 55.299 months, and the 1-, 3and 5-year survival rates were $95 \%, 91 \%$ and $86 \%$, respectively, while the survival rate of high expression group was 36.324 months.

The univariate survival analysis indicated that the survival rates of patients with low expression of CD24 $\left(\chi^{2}=14.546\right.$, $\mathrm{P}=0.000)$ or Lyn $\left(X^{2}=12.559, \mathrm{P}=0.000\right)$ was higher than that of patients with high expression ( $\log$ rank, $\mathrm{P}<0.05$; Figure 6 and Table 3). Other factors that were associated with tumor prognosis included tumor size, tumor stage, and lymph node and distant metastasis $(\mathrm{P}<0.05)$.

The Cox multivariate analysis showed that the expression of CD24 $(\mathrm{P}=0.020, \mathrm{RR}=2.918,95 \% \mathrm{CI}$ : 1.188 7.166), but not Lyn expression, could be used as an independent prognostic factor. Our data also showed that 
Table 2 Correlation of CD24 and Lyn expression and clinic-pathological parameters in 202 CRC patients

\begin{tabular}{|c|c|c|c|c|c|c|c|c|c|c|c|c|c|c|c|}
\hline \multirow[b]{2}{*}{ Item } & \multirow[b]{2}{*}{ Case } & \multicolumn{4}{|c|}{ CD24 } & \multirow[b]{2}{*}{$\begin{array}{l}\text { Mean } \\
\text { ranks }\end{array}$} & \multirow[b]{2}{*}{$z / x^{2} / r$} & \multirow[b]{2}{*}{$P$} & \multicolumn{4}{|c|}{ Lyn } & \multirow[b]{2}{*}{$\begin{array}{l}\text { Mean } \\
\text { ranks }\end{array}$} & \multirow[b]{2}{*}{$z / x^{2} / r$} & \multirow[b]{2}{*}{$P$} \\
\hline & & - & + & ++ & +++ & & & & - & + & ++ & +++ & & & \\
\hline \multicolumn{16}{|l|}{ *Gender } \\
\hline Male & 110 & 2 & 58 & 38 & 12 & 100.35 & -0.336 & 0.737 & 9 & 54 & 38 & 9 & 98.92 & -0.749 & 0.454 \\
\hline Female & 92 & 4 & 40 & 42 & 6 & 102.87 & & & 5 & 44 & 34 & 9 & 104.59 & & \\
\hline \multicolumn{16}{|l|}{${ }^{*}$ Age(years) } \\
\hline$\leq 60$ & 112 & 4 & 57 & 45 & 6 & 96.79 & -1.407 & 0.159 & 8 & 56 & 40 & 8 & 99.14 & -0.698 & 0.485 \\
\hline$>60$ & 90 & 2 & 41 & 35 & 12 & 107.36 & & & 6 & 42 & 32 & 10 & 104.43 & & \\
\hline \multicolumn{16}{|l|}{ \#Localization } \\
\hline Right colon & 32 & 1 & 15 & 14 & 2 & 101.44 & 0.02 & 0.990 & 2 & 19 & 8 & 3 & 93.44 & 1.217 & 0.544 \\
\hline Left colon & 68 & 1 & 34 & 29 & 4 & 100.81 & & & 4 & 30 & 27 & 6 & 106.05 & & \\
\hline Rectum & 102 & 4 & 49 & 37 & 12 & 101.98 & & & 8 & 49 & 37 & 9 & 101.04 & & \\
\hline \multicolumn{16}{|l|}{ *Tumor size } \\
\hline$\leq 5 \mathrm{~cm}$ & 155 & 4 & 78 & 58 & 15 & 100.82 & -0.333 & 0.739 & 9 & 80 & 54 & 12 & 99.93 & -0.759 & 0.448 \\
\hline$>5 \mathrm{~cm}$ & 47 & 2 & 20 & 22 & 3 & 103.76 & & & 5 & 18 & 18 & 6 & 106.69 & & \\
\hline \multicolumn{16}{|l|}{ \&Grade } \\
\hline G1 & 99 & 3 & 58 & 34 & 4 & & 0.255 & 0.000 & 6 & 58 & 30 & 5 & & 0.233 & 0.000 \\
\hline G2 & 64 & 2 & 30 & 26 & 6 & & & & 6 & 31 & 23 & 4 & & & \\
\hline G3 & 39 & 1 & 10 & 20 & 8 & & & & 2 & 9 & 19 & 9 & & & \\
\hline \multicolumn{16}{|l|}{ \&Tumor stage } \\
\hline I & 30 & 2 & 22 & 6 & 0 & & 0.577 & 0.000 & 3 & 20 & 5 & 4 & & 0.399 & 0.000 \\
\hline$\|$ & 85 & 2 & 62 & 20 & 1 & & & & 8 & 59 & 17 & 3 & & & \\
\hline III & 50 & 1 & 12 & 32 & 5 & & & & 2 & 12 & 31 & 3 & & & \\
\hline IV & 37 & 1 & 2 & 22 & 12 & & & & 1 & 7 & 19 & 8 & & & \\
\hline \multicolumn{16}{|l|}{ \&Invasion depth } \\
\hline $\mathrm{T} 1$ & 38 & 2 & 24 & 10 & 2 & & 0.293 & 0.000 & 5 & 22 & 9 & 2 & & 0.297 & 0.000 \\
\hline $\mathrm{T} 2$ & 98 & 1 & 55 & 37 & 5 & & & & 4 & 58 & 30 & 6 & & & \\
\hline $\mathrm{T} 3$ & 44 & 2 & 17 & 22 & 3 & & & & 4 & 16 & 20 & 4 & & & \\
\hline T4 & 22 & 1 & 2 & 11 & 8 & & & & 1 & 2 & 13 & 6 & & & \\
\hline \multicolumn{16}{|c|}{ *Lymph node metastasis } \\
\hline Negative & 130 & 5 & 84 & 38 & 3 & 82.70 & -6.770 & 0.000 & 11 & 81 & 31 & 7 & 86.03 & -5.516 & 0.000 \\
\hline Positive & 72 & 1 & 14 & 42 & 15 & 135.44 & & & 3 & 17 & 41 & 11 & 129.43 & & \\
\hline \multicolumn{16}{|c|}{ *Distant metastasis } \\
\hline Negative & 162 & 4 & 96 & 60 & 2 & 88.88 & -6.805 & 0.000 & 13 & 89 & 52 & 8 & 92.71 & -4.694 & 0.000 \\
\hline Positive & 40 & 2 & 2 & 20 & 16 & 152.60 & & & 1 & 9 & 20 & 10 & 137.10 & & \\
\hline
\end{tabular}

tumor distant metastasis $(\mathrm{P}=0.008, \mathrm{RR}=4.396,95 \% \mathrm{CI}$ : $1.475-13.105)$ and tumor stage $(P=0.019, R R=2.289$, 95\% CI: 1.146 - 4.573) were also independent prognostic factors for CRC patients (Table 4).

\section{Discussion}

It is reported that SFKs are over-expressed and activated in a large number of human malignancies. SFKs have been found to be associated with the development of cancer and progression to distant metastasis, including
CRC [18,21]. More interesting, GPI-anchored proteinsrelated signaling transduction is also mediated by SFKs [22]. In our previous study, we found that ERK1/2 was involved in CD24-induced CRC cell proliferation [7] and invasion. In the present study, we aimed to investigate the role of SFKs in this cellular process. Therefore, we first detected the effects of CD24 on the activity of SFKs in CRC cells by Western blotting. We found that CD24 could increase the expression of phospho-Lyn (Y396), but not phospho-Src, phospho-Fyn or phospho-lck in 


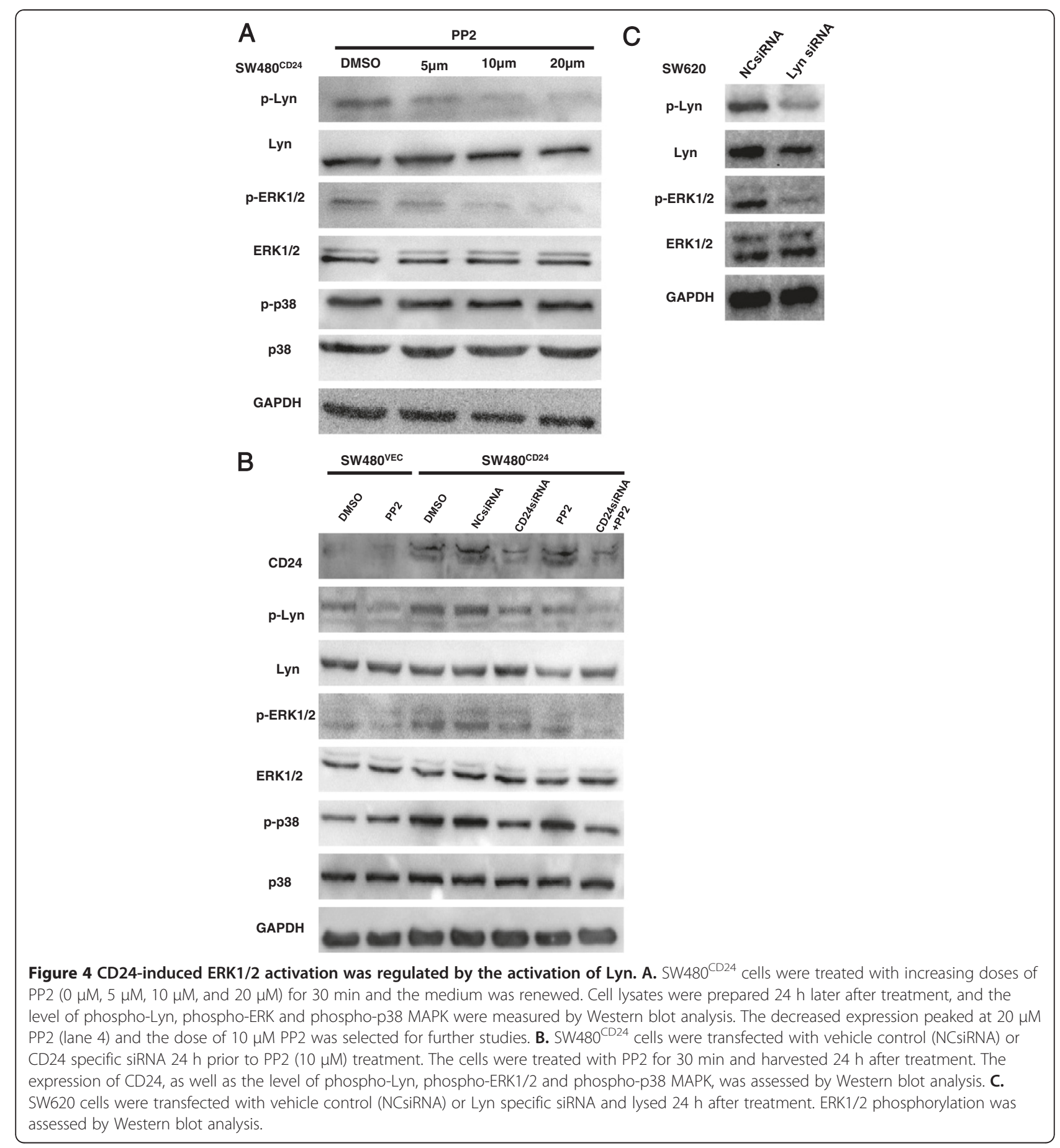

CRC cells, which indicated a tumor-type dependent induction. Three research groups $[12,23,24]$ reported that CD24 interacted with Lyn directly or indirectly in monocytic ESb-MP cells, in the erythroleukaemia cell line K562 and in the Burkitt's lymphoma (BL)-derived cell line $\mathrm{P} 32 / \mathrm{SH}$. Therefore, we hypothesized that there was an interaction between CD24 and Lyn directly or indirectly in CRC. Through CO-IP assays, we identified this interaction in $\mathrm{CRC}$, and this might be the first report of an interaction between CD24 and Lyn in solid tumors. To identify the interaction between CD24 and Lyn in vivo, we examined the expression of CD24 and Lyn by immunohistochemical staining on serial sections of CRC tissues. The results showed that the expression of CD24 was positively correlated with phospho-Lyn expression in 202 CRC patients.

Mierke et al. found that CD24 enhanced human lung cancer cell invasion through increased generation or 


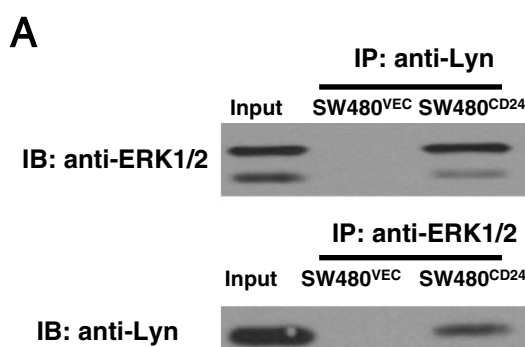

C
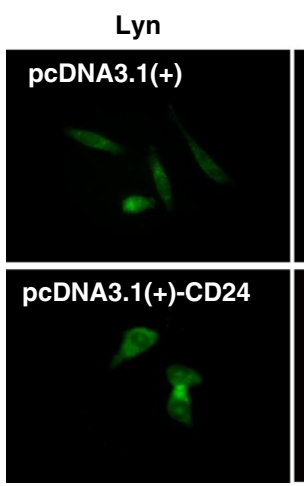

ERK1/2
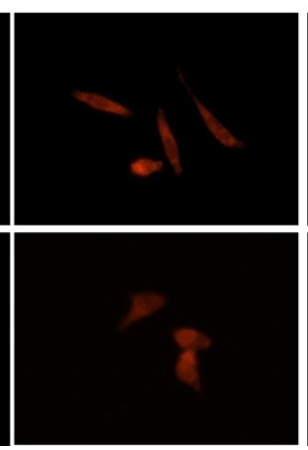

B

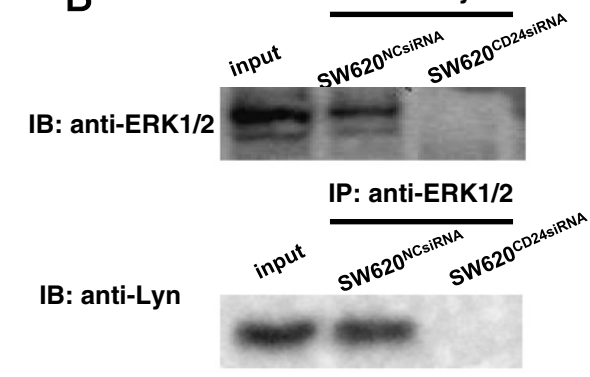

DAPI

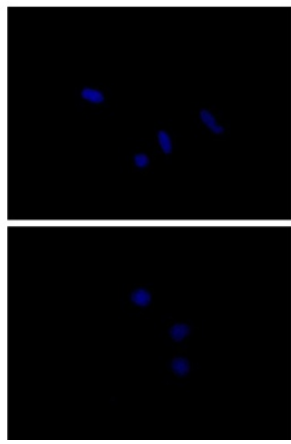

Merge

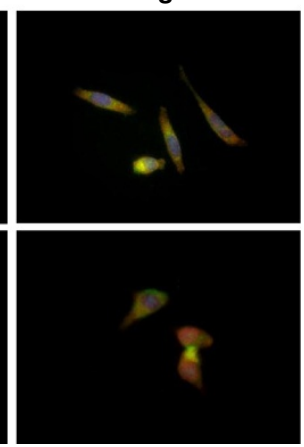

Figure 5 The interaction between Lyn and ERK1/2. A. The interaction between Lyn and ERK1/2 was detected in SW480 CD24 and SW480VEC cells. Cell lysates were immunoprecipitated by an anti-Lyn antibody and assayed by Western blotting with an anti-ERK1/2 antibody. Normal rabbit IgG served as a control. B. SW620 cells were transiently transfected with CD24 siRNA. Cell lysates were immunoprecipitated by an anti-Lyn antibody and assayed by Western blotting analysis with a ERK1/2 antibody. Pictures are representatives of two or three independent experiments with identical results. C. Immunofluorescent staining of SW620 cells transfected with CD24 siRNA. SW620 cells were transiently transfected with CD24siRNA or vehicle control for $24 \mathrm{~h}$. Cytosolic and nucleus location of Lyn (green) and ERK1/2 (red) were examined by primary antibodies followed by FITC-conjugated secondary antibodies and visualized under fluorescent microscopy (original magnification=630x, Oil). The nucleus was stained with 4, 6-diamidino-2-phenylindole (DAPI; blue). phospo-Lyn and phospho-ERK1/2 signals were greater and intense in the nucleus.

transmission of contractile forces [25]. In the present study, we also found that overexpression of CD24 could increase the cell invasion ability. Furthermore, we investigated the role of Lyn in CD24- induced CRC cell invasion. After treating cells with PP2, a specific inhibitor of SFKs, CD24-induced CRC cell invasion was abrogated, suggesting that Lyn was involved in CD24-induced cell invasion. SFKs are known to be ubiquitously distributed in the cell membrane, but Src is located in perinuclear membranes, endosomes and possibly even the nucleus, implicating the involvement of $\mathrm{Src}$ in nuclear-signal transduction events [26]. The regulation of nucleocytoplasmic distribution of Lyn contributes to the association of Lyn with other upstream or downstream signaling molecules. To elucidate the underlying mechanisms in this process, we examined the subcellular localization of Lyn by immunoflourescence staining. In SW $480^{\text {VEC }}$ cells, positive cellular signals of Lyn was predominant in the cytoplasm, and over-expression of CD24 resulted in a cytosolic decrease and a nuclear accumulation of Lyn. The nuclear translocation strongly implied that the regulation of gene transcription of Lyn might be involved, which should be clarified in further studies. In addition, we found that Lyn and CD24 were expressed in different tumor stages of CRC and the expression level of CD24 and Lyn was positively correlated with tumor grade, tumor stage, invasion depth, and lymph node and distant metastasis.

SFKs are the upstream modulator of MAP kinases in several receptor signaling pathways. Therefore, it is possible that CD24 directly or indirectly interacts with Lyn and affects the activity of ERK1/2. We found that the depletion of CD24 and Lyn, by specific siRNA or inactivation of Lyn by its specific inhibitor PP2, could reduce the phosphorylation level of ERK1/2 respectively or synergistically. CO-IP assays showed that Lyn interacted with ERK1/2 in a CD24 high expression cell line and the Lyn-ERK interaction was disrupted by the depletion of CD24, suggesting that Lyn was involved in CD24induced ERK1/2 activation in CRC cells. Therefore, it is possible that CD24 directly or indirectly induces the activation of Lyn and promotes the interaction and nuclear translocation of Lyn, leading to cell invasion. To better understand the Lyn-ERK1/2 interaction and the related 

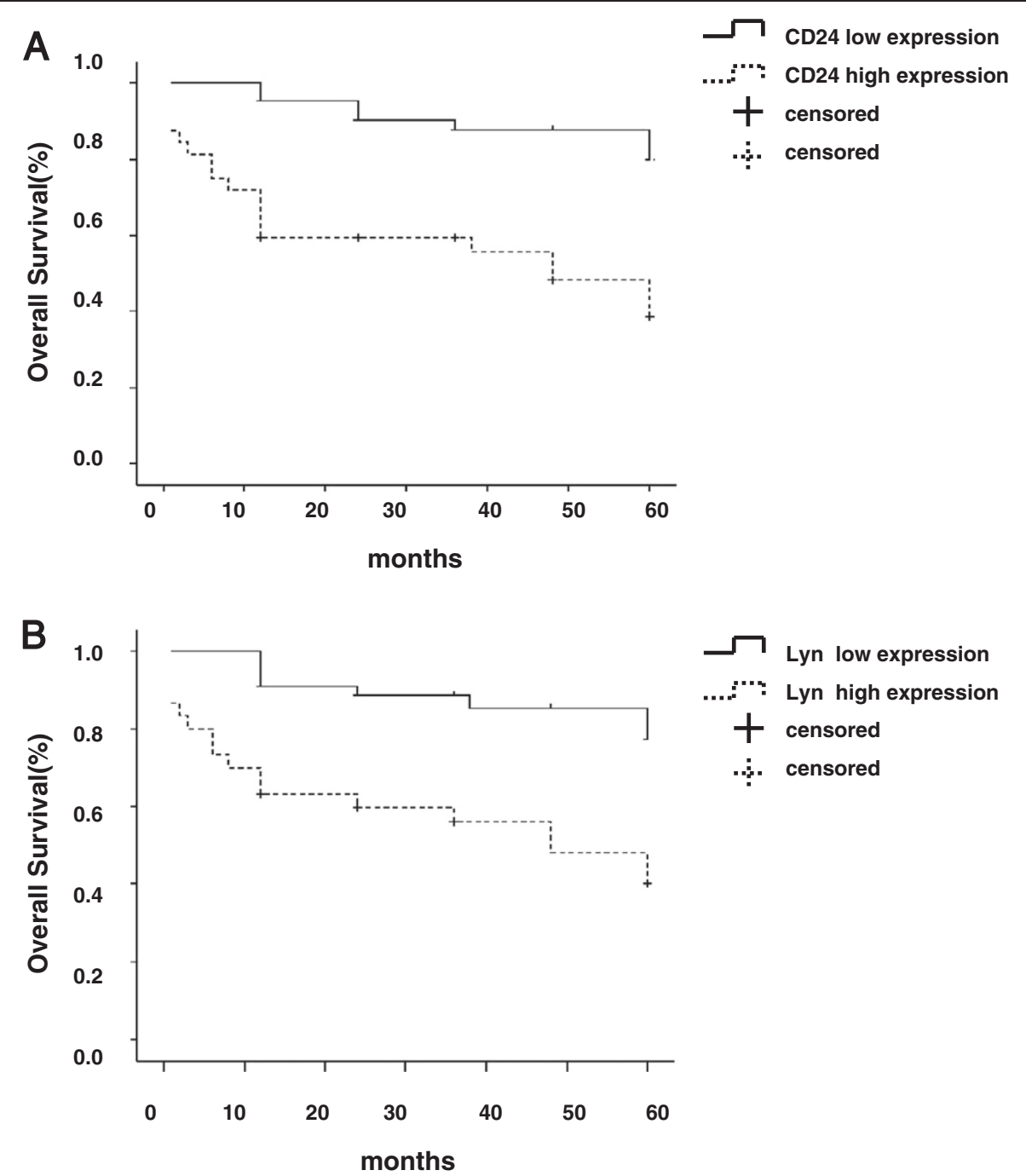

Figure 6 Kaplan-Meier survival curves of 74 CRC patients relating to the status of CD24 (A) and Lyn (B) expression. The log-rank test was used to calculate $P$ values (CD24: $P=0.020)$.

regulation, further investigations are required to characterize the interaction site or structure among CD24, Lyn and ERK1/2 on the membrane, such as glycolipid-enriched membrane (GEM) domains or nucleus.

The studies on the roles of CD24 and Lyn in CRC invasion provided potential targets for CRC diagnosis and prognosis. However, the clinicopathologic significance of CD24 is still controversial $[7,27,28]$ and very few studies have elucidated the relationship between Lyn and clinicopathological characteristics of CRC. Sagiv et al. [6] showed that CD24 was expressed in $90.7 \%$ of adenomas and $86.3 \%$ of CRC. In addition, recent studies suggested that CD24 was a promising therapeutic target in cancers of the gastrointestinal tract and bladder cancer metastasis [29-31]. In our study, strong expression of cytoplasmic CD24 correlated significantly to shortened survival of CRC patients without distant metastases [28]. However, studies from Ahmed et al. [32] and Choi et al. [33] showed early CD24 up-regulation and nuclear expression, but it was not a prognostic marker for CRC. Hao et al. [21] showed that Lyn was significantly correlated with overall survival in CRC patients. In the present study, the Cox multivariate analysis showed that CD24, tumor distant metastasis and tumor stage were independent prognostic factors of CRC patients. In contrast, Lyn was not an independent prognostic factor of CRC, which is different from previously reported studies.

In this study, we showed that Lyn was involved in CD24-induced ERK1/2 activation and CRC cell invasion in vitro. In vivo, we found aberrant CD24 and Lyn expression in the majority of the CRC tissues and a significant correlation between CD24 and Lyn. CD24 was identified as an independent prognostic factor of CRC, 
Table 3 Univariate survival analysis of 74 CRC patients

\begin{tabular}{|c|c|c|c|}
\hline Factors & Case $(n)$ & $x^{2}$ & $P$ \\
\hline \multicolumn{4}{|l|}{ Sex } \\
\hline Males & $45 / 15$ & 0.027 & 0.869 \\
\hline Female & 29/10 & & \\
\hline \multicolumn{4}{|l|}{ Age } \\
\hline$\leq 60 y$ & $37 / 13$ & 0.103 & 0.748 \\
\hline$>60 y$ & $37 / 12$ & & \\
\hline \multicolumn{4}{|l|}{ Localization } \\
\hline Right colon & $14 / 3$ & 4.530 & 0.104 \\
\hline Left colon & $18 / 8$ & & \\
\hline Rectum & $42 / 14$ & & \\
\hline \multicolumn{4}{|l|}{ Tumor size } \\
\hline$\leq 5 \mathrm{~cm}$ & $50 / 21$ & 4.777 & 0.029 \\
\hline$>5 \mathrm{~cm}$ & $24 / 4$ & & \\
\hline \multicolumn{4}{|l|}{ Grade } \\
\hline G1 & $36 / 10$ & 4.867 & 0.088 \\
\hline G2 & $26 / 8$ & & \\
\hline G3 & $12 / 7$ & & \\
\hline \multicolumn{4}{|l|}{ Invasion Depth } \\
\hline $\mathrm{T} 1$ & $8 / 1$ & 2.297 & 0.513 \\
\hline $\mathrm{T} 2$ & $35 / 11$ & & \\
\hline T3 & $28 / 12$ & & \\
\hline T4 & $3 / 1$ & & \\
\hline \multicolumn{4}{|l|}{ Tumor stage } \\
\hline I & $8 / 0$ & 36.033 & 0.000 \\
\hline$\|$ & $26 / 1$ & & \\
\hline III & $21 / 10$ & & \\
\hline IV & $19 / 14$ & & \\
\hline \multicolumn{4}{|l|}{ Lymph node } \\
\hline Negative & $42 / 8$ & 13.972 & 0.000 \\
\hline Positive & $32 / 17$ & & \\
\hline \multicolumn{4}{|c|}{ Distant metastasis } \\
\hline Negative & $55 / 10$ & 50.535 & 0.000 \\
\hline Positive & 19/15 & & \\
\hline \multicolumn{4}{|l|}{ CD24 } \\
\hline low & $42 / 7$ & 14.456 & 0.000 \\
\hline high & $32 / 18$ & & \\
\hline \multicolumn{4}{|l|}{ Lyn } \\
\hline low & $44 / 8$ & 12.559 & 0.000 \\
\hline high & $30 / 17$ & & \\
\hline
\end{tabular}

and the expression of CD24 was associated with the activation of Lyn and ERK1/2, which might be a novel mechanism related to CD24-mediated regulation of CRC development.

\section{Materials and methods Reagents and antibodies}

RPMI-1640 medium and FBS were purchased from Life Technologies (Grand Island, NY). G418 was obtained from Calbiochem (San Diego, CA). The PP2 inhibitor was purchased from Sigma (St. Louis, MO). ERK1/2 (137 F5), phospho-ERK1/2 (Thr202/Tyr204), p38 MAPK, phosphop38 MAPK (Thr180/Tyr186), SAPK/JNK, phospho-SAPK/ JNK (Thr183/Tyr185), Lyn (C13F9), Src, and phospho-Src (TYR416) antibodies were purchased from Cell Signaling Technology (Danvers, MA). The phospho-Lyn (Y396) antibody was purchased from Abcam (Cambridge, MA). CD24 (C-20), GAPDH, phospho-Fyn (Thr12), Fyn, phospho-lck (Tyr394) and lck antibodies, FITC-antibody, and Lyn siRNA were purchased from Santa Cruz Biotechnology (Santa Cruz, CA).

\section{Tissue samples}

Formalin-fixed, paraffin-embedded tissue samples from 202 (110 men and 92 women) primary CRC patients were randomly obtained and processed by routine clinical histopathological methods. The patients had a mean age of 57 years (range 18-87 years) and a median age of 59 years. The pathological tumor stages were determined according to the TNM classification of the American Joint Committee on Cancer Criteria, and the World Health Organization (WHO) classification of tumors was used to determine the histological grade. Clinical follow-up data were available for 74 patients, while 128 patients were excluded for lack of information. The study was carried out in accordance with the institutional ethical guidelines and was approved by the Medical Ethics Committee of Southern Medical University. Informed consent was obtained from all patients.

\section{Cell culture and treatments}

SW480 and SW620 cell lines were obtained from American Type Culture Collection (Rockville, MD). SW480 ${ }^{\mathrm{CD} 24}$ and SW480 ${ }^{\mathrm{VEC}}$ cells were established, as described in a previous study [7]. Cells were maintained in RPMI-1640 medium supplemented with 10\% FBS (complete medium) and $1000 \mu \mathrm{g} / \mathrm{ml} \mathrm{G418}$ at $37^{\circ} \mathrm{C}$ with an atmosphere of $5 \%$ $\mathrm{CO}_{2}$ and subcultured by digestion with $0.05 \%$ trypsin. For PP2 treatment, cells were seeded in serum-free medium overnight, followed by the addition of PP2 as indicated for $30 \mathrm{~min}$ at $37^{\circ} \mathrm{C}$. Medium containing the PP2 inhibitor was renewed after $30 \mathrm{~min}$ of incubation.

\section{RT-PCR}

Total RNA was isolated from cells using Trizol (Invitrogen). Next, $2 \mu \mathrm{g}$ of RNA sample was subjected to reverse transcription using a RevertAid First Strand cDNA Synthesis Kit (K1622, Fermentas, MBI, Vilnius, Lithuania). The primer pairs for CD24 were 5'- 
Table 4 Multivariate analysis of prognostic factors in 74 CRC patients

\begin{tabular}{|c|c|c|c|c|c|c|c|c|}
\hline & \multirow[t]{2}{*}{ B } & \multirow[t]{2}{*}{ SE } & \multirow[t]{2}{*}{ Wald } & \multirow[t]{2}{*}{ df } & \multirow[t]{2}{*}{$P$} & \multirow[t]{2}{*}{ RR } & \multicolumn{2}{|c|}{$95.0 \% \mathrm{Cl}$ for $\operatorname{Exp}(\mathrm{B})$} \\
\hline & & & & & & & Lower & Upper \\
\hline Tumor stage & 0.828 & 0.353 & 5.499 & 1 & 0.019 & 2.289 & 1.146 & 4.573 \\
\hline Distant Metastasis & 1.481 & 0.557 & 7.059 & 1 & 0.008 & 4.396 & 1.475 & 13.105 \\
\hline CD24 & 1.071 & 0.458 & 5.456 & 1 & 0.020 & 2.918 & 1.188 & 7.166 \\
\hline
\end{tabular}

TAGGTACCACTATGGGCAGAGCAATGG-3' (forward) and 5'-CCGGAATTCCGTTAAGAGTAGAGATGC-3' (reverse). The primer pairs for GAPDH were 5'GTCAACGGATTTGGTCGTATTG-3' (forward) and 5'CTCCTGGAAGATGGTGATGGG-3' (reverse). PCR was initiated by 5 min incubation at $94^{\circ} \mathrm{C}, 36$ cycles of denaturation at $94^{\circ} \mathrm{C}$ for $45 \mathrm{~s}$, annealing at $56^{\circ} \mathrm{C}$ and extension at $72^{\circ} \mathrm{C}$ for $50 \mathrm{~s}$, and ended after a $7 \mathrm{~min}$ extension at $72^{\circ} \mathrm{C}$ using a PCR kit (SBS, Beijing, China). The experiments were repeated twice and GAPDH mRNA was amplified simultaneously as an internal control.

\section{Preparation of siRNA and transfection}

A siRNA duplex targeting CD24 and a negative control sequence were designed and synthesized by GenePharma Co. (Shanghai, China). The target sequence of the CD24 siRNA duplex was as follows: CD24 siRNA sense 5'GAUUUAUUCCA GUGAAACATT-3' and antisense 5'UGUUUCACUGGAAUA AAUCTG-3'. The negative control sequence was as follows: sense 5'-CUACCUA UGCAGAUUU AUUdTdT-3' and antisense 5'-AAUAAA UCUGCAUAGGUAGdTdT-3'. BLAST research confirmed the unique sequence of the siRNA. Lyn siRNA was purchased from Santa Cruz Biotechnology (sc29393, Santa Cruz, CA). The specific and negative control siRNAs were transfected into SW480 ${ }^{\mathrm{CD} 24}$ and/or SW620 cells $24 \mathrm{~h}$ prior to Western blotting analyses or cell invasion assays using lipofectamine ${ }^{\mathrm{TM}} 2000$ reagent according to the manufacturer's instructions.

\section{Western blotting analysis}

Whole cell lysates were prepared as described previously [34]. Equal aliquots of total cell lysates $(30 \mu \mathrm{g})$ were electrophoresed on denaturing sodium dodecy1 sulfatepolyacrylamide gel electrophoresis (SDS-PAGE) gels (5\% stacking gel and $8 \%-12 \%$ resolving gel). The proteins were then transferred to polyvinylidene difluoride (PVDF) membranes (Millipore, Bedford, MA). The blots were probed with primary antibodies followed by the horseradish peroxidase-conjugated secondary antibody. Antigenantibody complexes were visualized using an enhanced chemiluminescence system (Amersham Biosciences, Little Chalfont Buchkinghamshire, UK). GAPDH served as the loading control.

\section{Immunofluorescence}

Immunofluorescent staining was performed as described [35]. In brief, cells grown on cover glass were fixed in phosphate-buffered saline (PBS) containing $4 \%$ paraformaldehyde for $30 \mathrm{~min}$ at room temperature. Nonspecific binding was blocked by incubation with $1 \%$ bovine serum albumin (BSA). Cells were subsequently reacted with an appropriate primary antibody for $1 \mathrm{~h}$, then washed and stained with TR-or fluorescein isothiocyanate-conjugated second antibodies. After mounting with Prolong Antifade ${ }^{\mathrm{mm}}$ reagent (Molecular Probes), the cells were visualized under an Olympus CKX41 fluorescence microscope (Olympus, Tokyo, Japan).

\section{Co-IP}

As described previously [36], $2 \mathrm{mg}$ of cell lysates from control or transfected cells were incubated with $3 \mu \mathrm{g}$ of primary antibody overnight at $4^{\circ} \mathrm{C}$ on an oscillation shaker. Then, $50 \mu \mathrm{l}$ of suspension, with a 1:1 ratio of protein A-Sepharose beads, were added and incubated for $2 \mathrm{~h}$ at $4^{\circ} \mathrm{C}$ with gentle rotation. After extensive washing, precipitates were subjected to Western blotting analyses for detection of potential interacting proteins. Normal rabbit IgG served as a negative control.

\section{Cell invasion assay}

Cell invasion was assessed using an invasion assay kit (ECM551, Millipore, Bedford, MA) [37] according to manufacturer's instructions. The cells, which were treated according to different experimental purposes, were suspended in serum free RPMI-1640 medium at a density of $1.0 \times 10^{6} / \mathrm{ml}$. Next, $300 \mu$ of the prepared cell suspension and $500 \mu \mathrm{l}$ of RPMI-1640 containing $10 \%$ FBS were respectively added in each insert and the matched lower chamber and incubated for additional $24 \mathrm{~h}$. Non-invaded cells were removed with cotton swabs. Invasive cells were stained with $0.2 \%$ crystal violet and counted under a microscope. Six random fields for each insert were counted (per HPF $\times 200$ ).

\section{Immunohistochemical analysis and evaluation}

The Medical Ethics Committee of Southern Medical University approved our experimental protocols. Paraffin-embedded tissue blocks were cut into $4 \mu \mathrm{m}$ 
sections and transferred to glass slides. The slides were deparaffinized with xylene, rehydrated with ethanol, washed, and subjected to microwave retrieval in a citrate buffer. Sections were then immersed in 3\% hydrogen peroxide to block endogenous peroxidase activity and incubated with primary antibodies at $4^{\circ} \mathrm{C}$ overnight followed by incubation with goat or rabbit serum for 30 min the next day. Subsequent steps utilized the UltraSensitive $^{\text {TM }}$ SP kit (KIT-0310, Maxin_bio, Fuzhou, China) according to the manufacturer's instructions. The expressions of CD24 and Lyn were visualized using DAB and counterstained with hematoxylin. Tissues were considered "positive" when $10 \%$ or more of the cancer cells were positively stained [38]. For quantitative analysis, the ratio of positively stained cells to all tumor cells in five random areas at 200X and/or 400X magnification was recorded.

\section{Statistical analysis}

Statistical analysis was performed using the software package SPSS 13.0. ANOVA provided a statistical test used to determine the results of cell invasion assay. Non-parametric Kruskal-Wallis or Mann-Whitney tests were used to test the differences between subgroups of clinic-pathological parameters, whereas the correlations of the expression of different proteins were evaluated by the Spearman rank-order correlation coefficient. Kaplan-Meier and Log-rank tests analyzed the univariate prognostic analysis, qualifying into the COX proportional hazards model for multivariate analysis. The level of significance was defined as $P<0.05$.

\section{Additional file}

Additional file 1: Supplementary figures. Figure S1: Densitometry results of Figure 1A; Figure S2: CD24 siRNA-2 results; Figure S3: Means \pm standard errors (SE) for three independent experiments for Figure 4

\section{Abbreviations}

BSA: bovine serum albumin; Co-IP: co-immunoprecipitation; CRC: colorectal cancer; ERK1/2: extracellular signal-regulated kinases 1 and 2; GEM: glycolipid-enriched membrane; PBS: phosphate-buffered saline; PVDF: polyvinylidene difluoride; SDS-PAGE: sodium dodecy1 sulfatepolyacrylamide gel electrophoresis; SFKs: Src family kinases; WHO: World Health Organization.

\section{Competing interests}

The authors declare that they have no competing interests.

\section{Author's contributions}

NS and LP participated in the design of the study, and carried out the experiment, and performed the statistical analysis. BX, YZ, AX and JW participated in the experiment and drafted the manuscript. XW and BJ conceived of the study, and participated in its design and coordination and edited the manuscript. All authors read and approved the final manuscript.

\section{Acknowledgements}

This work was supported by grants from National Natural Science

Foundation of China (30971520). We thank Dr. Shengli An in Department of
Statistics, Southern Medical University, Guangzhou for his expert assistance for the statistical analysis in this study.

\section{Author details}

'Department of Gastroenterology, Nanfang Hospital, Southern Medical University, Guangzhou 510515, China. ${ }^{2}$ Guangdong Provincial key laboratory of Gastroenterology, Guangzhou 510515, China. ${ }^{3}$ Huizhou Medical Institute, Huizhou, Guangdong 516001, China.

Received: 3 February 2012 Accepted: 26 June 2012

Published: 26 June 2012

\section{References}

1. Kristiansen $G$, Sammar M, Altevogt P: Tumour biological aspects of CD24, a mucin-like adhesion molecule. J Mol Histol 2004, 35:255-262.

2. Kristiansen G, Winzer KJ, Mayordomo E, Bellach J, Schluns K, Denkert C, Dahl E, Pilarsky C, Altevogt P, Guski H, Dietel M: CD24 expression is a new prognostic marker in breast cancer. Clin Cancer Res 2003, 9:4906-4913.

3. Kristiansen G, Pilarsky C, Pervan J, Sturzebecher B, Stephan C, Jung K, Loening S, Rosenthal A, Dietel M: CD24 expression is a significant predictor of PSA relapse and poor prognosis in low grade or organ confined prostate cancer. Prostate 2004, 58:183-192.

4. Agrawal S, Kuvshinoff BW, Khoury T, Yu J, Javle MM, LeVea C, Groth J, Coignet LJ, Gibbs JF: CD24 expression is an independent prognostic marker in cholangiocarcinoma. J Gastrointest Surg 2007, 11:445-451.

5. Chou YY, Jeng YM, Lee TT, Hu FC, Kao HL, Lin WC, Lai PL, Hu RH, Yuan RH: Cytoplasmic CD24 expression is a novel prognostic factor in diffuse-type gastric adenocarcinoma. Ann Surg Oncol 2007, 14:2748-2758.

6. Sagiv E, Memeo L, Karin A, Kazanov D, Jacob-Hirsch J, Mansukhani M, Rechavi G, Hibshoosh H, Arber N: CD24 is a new oncogene, early at the multistep process of colorectal cancer carcinogenesis. Gastroenterology 2006, 131:630-639.

7. Wang W, Wang X, Peng L, Deng Q, Liang Y, Qing H, Jiang B: CD24dependent MAPK pathway activation is required for colorectal cancer cell proliferation. Cancer Sci 2010, 101:112-119.

8. Smith SC, Oxford G, Wu Z, Nitz MD, Conaway M, Frierson HF, Hampton G, Theodorescu D: The metastasis-associated gene CD24 is regulated by Ral GTPase and is a mediator of cell proliferation and survival in human cancer. Cancer Res 2006, 66:1917-1922.

9. Bretz N, Noske A, Keller S, Erbe-Hofmann N, Schlange T, Salnikov AV, Moldenhauer G, Kristiansen G, Altevogt P: CD24 promotes tumor cell invasion by suppressing tissue factor pathway inhibitor-2 (TFPI-2) in a c-Src-dependent fashion. Clin Exp Metastasis 2011,

10. Friederichs J, Zeller Y, Hafezi-Moghadam A, Grone HJ, Ley K, Altevogt P: The CD24/P-selectin binding pathway initiates lung arrest of human $A 125$ adenocarcinoma cells. Cancer Res 2000, 60:6714-6722

11. Chen GY, Tang J, Zheng P, Liu Y: CD24 and Siglec-10 selectively repress tissue damage-induced immune responses. Science 2009, 323:1722-1725.

12. Zarn JA, Zimmermann SM, Pass MK, Waibel R, Stahel RA: Association of CD24 with the kinase $c$-fgr in a small cell lung cancer cell line and with the kinase lyn in an erythroleukemia cell line. Biochem Biophys Res Commun 1996, 225:384-391.

13. Baumann P, Thiele W, Cremers N, Muppala S, Krachulec J, Diefenbacher M, Kassel O, Mudduluru G, Allgayer H, Frame M, Sleeman JP: CD24 interacts with and promotes the activity of c-src within lipid rafts in breast cancer cells, thereby increasing integrin-dependent adhesion. Cell Mol Life Sci 2011.

14. Pazdrak K, Schreiber D, Forsythe P, Justement L, Alam R: The intracellular signal transduction mechanism of interleukin 5 in eosinophils: the involvement of lyn tyrosine kinase and the Ras-Raf-1-MEK-microtubuleassociated protein kinase pathway. J Exp Med 1995, 181:1827-1834.

15. Bjorge JD, Jakymiw A, Fujita DJ: Selected glimpses into the activation and function of Src kinase. Oncogene 2000, 19:5620-5635.

16. Yeatman TJ: A renaissance for SRC. Nat Rev Cancer 2004, 4:470-480

17. Janas ML, Hodgkin P, Hibbs M, Tarlinton D: Genetic evidence for Lyn as a negative regulator of IL-4 signaling. J Immunol 1999, 163:4192-4198.

18. Choi YL, Bocanegra M, Kwon MJ, Shin YK, Nam SJ, Yang JH, Kao J, Godwin AK, Pollack JR: LYN is a mediator of epithelial-mesenchymal transition and a target of dasatinib in breast cancer. Cancer Res 2010, 70:2296-2306.

19. Park SI, Zhang J, Phillips KA, Araujo JC, Najjar AM, Volgin AY, Gelovani JG, Kim SJ, Wang Z, Gallick GE: Targeting SRC family kinases inhibits growth 
and lymph node metastases of prostate cancer in an orthotopic nude mouse model. Cancer Res 2008, 68:3323-3333.

20. Montero JC, Seoane S, Ocana A, Pandiella A: Inhibition of SRC family kinases and receptor tyrosine kinases by dasatinib: possible combinations in solid tumors. Clin Cancer Res 2011, 17:5546-5552.

21. Hao JM, Chen JZ, Sui HM, Si-Ma XQ, Li GQ, Liu C, Li JL, Ding YQ, Li JM: A five-gene signature as a potential predictor of metastasis and survival in colorectal cancer. J Pathol 2010, 220:475-489.

22. Sammar M, Aigner S, Altevogt P: Heat-stable antigen (mouse CD24) in the brain: dual but distinct interaction with P-selectin and L1. Biochim Biophys Acta 1997, 1337:287-294.

23. Sammar M, Gulbins E, Hilbert K, Lang F, Altevogt P: Mouse CD24 as a signaling molecule for integrin-mediated cell binding: functional and physical association with src-kinases. Biochem Biophys Res Commun 1997, 234:330-334.

24. Suzuki T, Kiyokawa N, Taguchi T, Sekino T, Katagiri YU, Fujimoto J: CD24 induces apoptosis in human $B$ cells via the glycolipid-enriched membrane domains/rafts-mediated signaling system. J Immunol 2001, 166:5567-5577.

25. Mierke CT, Bretz N, Altevogt P: Contractile Forces Contribute to Increased Glycosylphosphatidylinositol-anchored Receptor CD24-facilitated Cancer Cell Invasion. J Biol Chem 2011, 286:34858-34871.

26. Hayakawa F, Naoe T: SFK-STAT pathway: an alternative and important way to malignancies. Ann N Y Acad Sci 2006, 1086:213-222.

27. Lee JH, Kim SH, Lee ES, Kim YS: CD24 overexpression in cancer development and progression: a meta-analysis. Oncol Rep 2009, 22:1149-1156.

28. Weichert W, Denkert C, Burkhardt M, Gansukh T, Bellach J, Altevogt P, Dietel $M$, Kristiansen G: Cytoplasmic CD24 expression in colorectal cancer independently correlates with shortened patient survival. Clin Cancer Res 2005, 11:6574-6581.

29. Overdevest JB, Thomas S, Kristiansen G, Hansel DE, Smith SC, Theodorescu D: CD24 offers a therapeutic target for control of bladder cancer metastasis based on a requirement for lung colonization. Cancer Res 2011, 71:3802-3811.

30. Sagiv E, Starr A, Rozovski U, Khosravi R, Altevogt P, Wang T, Arber N: Targeting CD24 for treatment of colorectal and pancreatic cancer by monoclonal antibodies or small interfering RNA. Cancer Res 2008, 68:2803-2812

31. Shapira S, Shapira A, Starr A, Kazanov D, Kraus S, Benhar I, Arber N: An immunoconjugate of anti-CD24 and Pseudomonas exotoxin selectively kills human colorectal tumors in mice. Gastroenterology 2011, 140:935-946.

32. Ahmed MA, Al-Attar A, Kim J, Watson NF, Scholefield JH, Durrant LG, llyas M: CD24 shows early upregulation and nuclear expression but is not a prognostic marker in colorectal cancer. J Clin Pathol 2009, 62:1117-1122.

33. Choi D, Lee HW, Hur KY, Kim JJ, Park GS, Jang SH, Song YS, Jang KS, Paik SS: Cancer stem cell markers CD133 and CD24 correlate with invasiveness and differentiation in colorectal adenocarcinoma. World J Gastroenterol 2009, 15:2258-2264.

34. Wang $X$, Li M, Wang J, Yeung CM, Zhang H, Kung HF, Jiang B, Lin MC: The BH3-only protein, PUMA, is involved in oxaliplatin-induced apoptosis in colon cancer cells. Biochem Pharmacol 2006, 71:1540-1550.

35. Yamaguchi N, Nakayama Y, Urakami T, Suzuki S, Nakamura T, Suda T, Oku N: Overexpression of the Csk homologous kinase (Chk tyrosine kinase) induces multinucleation: a possible role for chromosome-associated Chk in chromosome dynamics. J Cell Sci 2001, 114:1631-1641.

36. Lee EJ, Seo SR, Um JW, Park J, Oh Y, Chung KC: NF-kappaB-inducing kinase phosphorylates and blocks the degradation of Down syndrome candidate region 1. J Biol Chem 2008, 283:3392-3400.

37. Albini A, Iwamoto Y, Kleinman HK, Martin GR, Aaronson SA, Kozlowski JM, McEwan RN: A rapid in vitro assay for quantitating the invasive potential of tumor cells. Cancer Res 1987, 47:3239-3245.

38. Jin SH, Akiyama Y, Fukamachi $H$, Yanagihara $K$, Akashi T, Yuasa Y: IQGAP2 inactivation through aberrant promoter methylation and promotion of invasion in gastric cancer cells. Int J Cancer 2008, 122:1040-1046.

doi:10.1186/1476-4598-11-43

Cite this article as: Su et al:: Lyn is involved in CD24-induced ERK1/2 activation in colorectal cancer. Molecular Cancer 2012 11:43.

\section{Submit your next manuscript to BioMed Central and take full advantage of:}

- Convenient online submission

- Thorough peer review

- No space constraints or color figure charges

- Immediate publication on acceptance

- Inclusion in PubMed, CAS, Scopus and Google Scholar

- Research which is freely available for redistribution 